\title{
THE ANALYSIS OF FORCE PARAMETERS IN DRAWING PROCESS OF HIGH CARBON STEEL WIRES IN CONVENTIONAL AND HYDRODYNAMIC DIES
}

\begin{abstract}
The paper analyzes force parameters in the process of multistage drawing of steel wires in conventional and hydrodynamic dies. The drawing process of the wire rod with a diameter of $5.5 \mathrm{~mm}$ for wires with a diameter of $1.70 \mathrm{~mm}$ was performed in 12 drafts with the usage of the multistage drawbench Koch KGT with the speed range of 5-25 m/s.

Modern software of multistage drawbenches allows direct reading of many parameters during the drawing process, including drawing power. The force and drawing stress in each drafts were determined relying on experimental measurements. A complement to the research was a theoretical analysis of the drawing process. The results of the theoretical studies were compared to those obtained by experiment.

The significant impact of the drawing speed on the force parameters of the drawing process in conventional and hydrodynamic dies was demonstrated. Depending on the real conditions of the drawing, ie. temperature, friction and lubrication, enhancing the drawing speed can result in both an increase and a decrease in drawing stress.
\end{abstract}

Keywords: wire, conventional and hydrodynamic dies, friction, drawing power, drawing stress

\section{Introduction}

The development of plastic working entails an increasingly better steel wire manufacturing technology. New-generation wire production machinery enable now new, more effective high-speed drawing technologies to be implemented in wire drawing plants. Literature reports [1,2] show that in drawing at high speeds, intensive heating of the top wire layer occurs, which leads to a change in friction conditions.

For the calculation of the energy-force parameters of the drawing process, empirical formulae and FEM-based computer programs known in the literature can be used $[3,4]$. The accuracy of calculation results obtained using those methods is closely dependent on the adopted boundary conditions, and particularly, on the magnitude of the preset friction coefficient.

Information on the effect of drawing speed on the drawing force and stress can be found in the literature [5-7]. This information shows that increasing the drawing speed may result in either an increase or decrease in drawing force, with its magnitude being dependent, among other factors, on the grade of steel and its hardening degree, wire surface treatment, the type of lubricants used and the drawing machines [8-10]. Nevertheless, these parameters have usually been determined for wires drawn under laboratory conditions on a testing machine or single-stage drawing machines at drawing speeds of up to $2 \mathrm{~m} / \mathrm{s}$. In study [11], an attempt was made to evaluate the effect of the speed of drawing in conventional dies on the drawing force, lubrication conditions and the friction coefficient. For the experimental measurement of the drawing force in the last draw, in the speed range of $2.5 \div 20 \mathrm{~m} / \mathrm{s}$, a tensometric apparatus was used, which included a tensometric bridge and a tensometric sleeve (Fig. 1). It was demonstrated that, in multi-stage drawing in conventional dies, the friction coefficient varied at the last drawing stage in the range of 0.065-0.09, depending on the drawing speed.

The reduction of the friction coefficient in the process of drawing at high speeds can be achieved by means of drawing under hydrodynamic lubrication conditions. Such conditions are assured by employing pressure dies in the drawing process. In respect of the friction coefficient value in the process of drawing in hydrodynamic dies, the views are divided. According to Avizur [12], it amounts to about 0.005 , while according to Golis and Dyja [13], it is contained in the range of $0.022 \div 0.032$. In the author's view, the friction coefficient in the hydrodynamic drawing process depends on the drawing process parameter, i.e. drawing speed, the lubricant, the material type, the single and total reductions, and the die design; hence the differences in the obtained friction coefficient values.

To sum up, in the multi-stage drawing process conducted at high speeds, the friction coefficient depends chiefly on the lubrication conditions. These conditions change in individual

\footnotetext{
CZESTOCHOWA UNIVERSITY OF TECHNOLOGY, INSTITUTE OF PLASTIC FORMING AND SAFETY ENGINEERING , 19 ARMII KRAJOWEJ AV., 42-200 CZĘSTOCHOWA, POLAND

Corresponding author: suliga@wip.pcz.p
} 

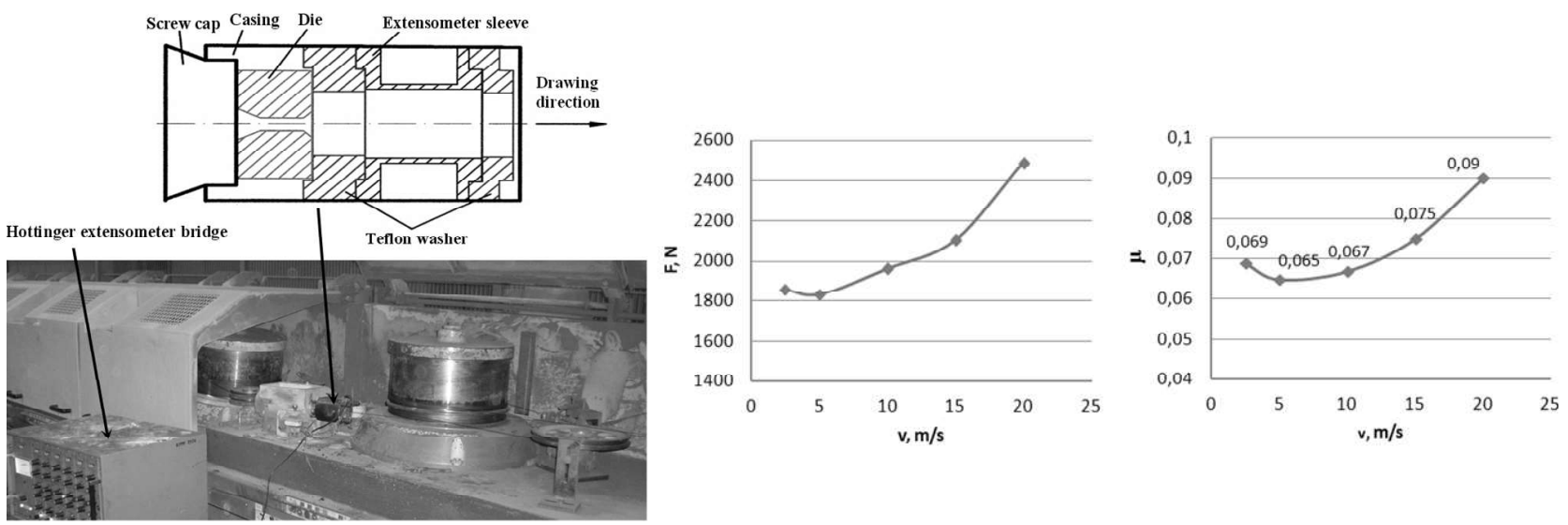

Fig. 1. The stand for the measurement of the drawing force on the Koch multi-stage drawing machine (drawing wire from the diameter of $\phi 1.85$ $\mathrm{mm}$ to $\phi 1.7 \mathrm{~mm}$ ) and the measured values of the drawing forces $F$ and the friction coefficients $\mu$ [11]

draws and depend on the speed of drawing in the last draw. Therefore, it seems essential to determine, under industrial conditions, parameters, such as power, force, drawing stress and wire temperature.

Based on numerical modelling and experimental studies, the analysis of the force parameters in the process of multi-stage drawing of steel wires in conventional and hydrodynamic dies has been performed in the paper.

\section{Material used for testing and drawing technologies applied}

The starting material for the process of multi-stage highspeed wire drawing in conventional and hydrodynamic dies was $5.5 \mathrm{~mm}$-diameter C78D grade high-carbon wire rod, which was drawn in twelve drawn into $1.7 \mathrm{~mm}$-diameter wire. The tests were carried out under industrial conditions in the ŻDB Dratovna a.s. drawing mill (the Czech Republic). Table 1 presents the distribution of single reductions, the total reduction and drawing speed in individual draws.

TABLE 1

Distribution of single reductions $G_{p}$, the total reduction $G_{c}$ and drawing speed $v$ in individual draws

\begin{tabular}{|c|c|c|c|c|c|c|c|c|}
\hline \multirow{2}{*}{ Draft } & \multirow{2}{*}{$\phi, \mathbf{m m}$} & \multirow{2}{*}{$G_{p}, \%$} & \multirow{2}{*}{$\boldsymbol{G}_{c}, \%$} & \multicolumn{5}{|c|}{$v, \mathrm{~m} / \mathrm{s}$} \\
\hline & & & & 1 & 2 & 3 & 4 & 5 \\
\hline 0 & 5.50 & - & - & - & - & - & - & - \\
\hline 1 & 5.00 & 17.4 & 17.4 & 0.58 & 1.16 & 1.73 & 2.31 & 2.89 \\
\hline 2 & 4.48 & 19.7 & 33.7 & 0.72 & 1.44 & 2.16 & 2.88 & 3.60 \\
\hline 3 & 4.00 & 20.3 & 47.1 & 0.90 & 1.81 & 2.71 & 3.61 & 4.52 \\
\hline 4 & 3.60 & 19.0 & 57.2 & 1.12 & 2.23 & 3.35 & 4.46 & 5.58 \\
\hline 5 & 3.24 & 19.0 & 65.3 & 1.38 & 2.75 & 4.13 & 5.51 & 6.88 \\
\hline 6 & 2.92 & 18.8 & 71.8 & 1.70 & 3.39 & 5.08 & 6.78 & 8.47 \\
\hline 7 & 2.64 & 18.3 & 77.0 & 2.07 & 4.15 & 6.22 & 8.29 & \begin{tabular}{|l|}
10.37 \\
\end{tabular} \\
\hline 8 & 2.40 & 17.4 & 81.0 & 2.51 & 5.02 & 7.53 & 10.04 & 12.54 \\
\hline 9 & 2.19 & 16.7 & 84.2 & 3.01 & 6.03 & 9.04 & 12.05 & 15.06 \\
\hline 10 & 2.01 & 15.8 & 86.6 & 3.58 & 7.15 & 10.73 & 14.31 & 17.88 \\
\hline 11 & 1.85 & 15.3 & 88.7 & 4.22 & 8.44 & 12.67 & 16.89 & 21.11 \\
\hline 12 & 1.70 & 15.6 & 90.5 & 5 & 10 & 15 & 20 & 25 \\
\hline
\end{tabular}

\section{Numerical analysis of the drawing process}

Mathematical modelling of the multi-stage high-speed drawing process was performed based on the Drawing 2D program [14], which enables the simulation of multi-stage wire drawing (with several consecutive single reductions), while considering the transfer of the strain tensor from draw to draw.

The simulation of the multi-stage drawing process was carried out for wire with the plastic properties of steel C75, as taken from the Drawing 2D program's database. It was assumed that the wire drawing process took place in conventional and hydrodynamic dies with an angle of $2 \alpha=12^{\circ}$ with reductions and at speeds, as given in Table 1 , and with a friction coefficient of $\mu=0.08$ for conventional drawing and $\mu=0.03$ for hydrodynamic drawing. The initial temperature of wire prior to entry to the first and subsequent dies was $20^{\circ} \mathrm{C}$.

The drawing stress in the high-speed wire drawing process was determined by analyzing the distribution of stress $\sigma_{y}$ (the longitudinal stress consistent with the drawing direction), obtained from drawing process simulation. Figure 2 shows an example of $\sigma_{y}$ longitudinal stress distribution in $\phi 1.7 \mathrm{~mm}$-gauge wires drawn in hydrodynamic dies at a drawing speed of $v=25 \mathrm{~m} / \mathrm{s}$.
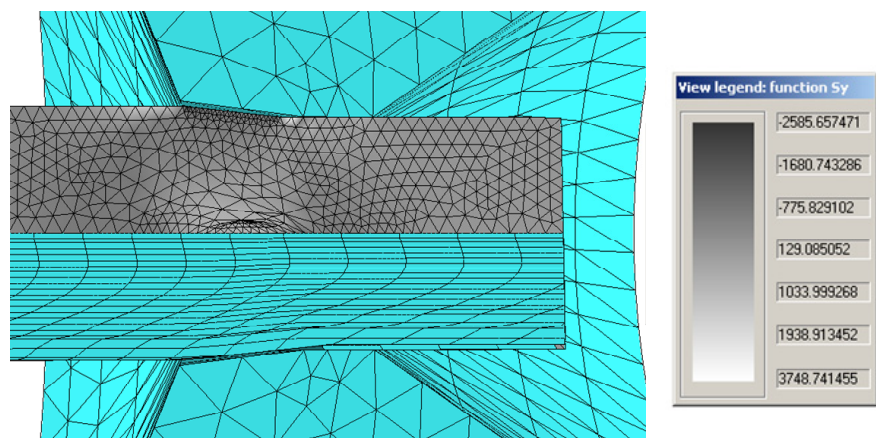

Fig. 2. A sample distribution of $\sigma_{y}$ longitudinal stress in finished $\phi 1.70$ $\mathrm{mm}$-gauge wires drawn in hydrodynamic dies at a drawing speed of $25 \mathrm{~m} / \mathrm{s}$

In the drawn material upon exist from the die, the longitudinal stress $\sigma_{y}$ is the sum of the drawing stress $\sigma_{c}$ and residual 
stresses of type I $\sigma_{w}$, namely:

$$
\sigma_{y}=\sigma_{c}+\sigma_{w}
$$

The analysis of the longitudinal stress was made in the following way: from the grid nodes located at the material exit from the die's sizing portion, stress values were red out along the line consistent with the wire radius. Then, the longitudinal stress $\sigma_{y}$, defined as a function of wire radius $R$, was approximated with a parabolic function of the second degree in the following form:

$$
\sigma_{y}=A R^{2}+C
$$

Study [15] suggest that for the determination of the drawing stress magnitude, the following relationship can be used:

$$
\sigma_{c}=1 / 3 A R^{2}+C
$$

The functions approximating the distribution of the longitudinal stress $\sigma_{y}$ as a function of the wire radius $R$, and the calculated values of the drawing stress $\sigma_{c}$ are given in Table 2 . Figure 3, on the other hand, shows the distributions of longitudinal stresses as a function of wire radius $\mathrm{R}$ for $\phi 1.7 \mathrm{~mm}$-gauge wires drawn at speed $25 \mathrm{~m} / \mathrm{s}$ in conventional and hydrodynamic dies, respectively.

TABLE 2

Functions approximating the $\sigma_{y}$ longitudinal stress distribution and $\sigma_{c}$ drawing stress values for $1.70 \mathrm{~mm}$-gauge wires drawn, respectively, in conventional and hydrodynamic dies

\begin{tabular}{|c|c|c|c|}
\hline \hline Type of dies & $\boldsymbol{v}, \mathbf{~ m} / \mathbf{s}$ & $\boldsymbol{\sigma}_{\boldsymbol{y}}=\boldsymbol{f}(\mathrm{R})$ & $\boldsymbol{\sigma}_{\boldsymbol{c}}, \mathbf{M P a}$ \\
\hline \multirow{4}{*}{ Conventional } & 5 & $\sigma_{y}=926,3 R^{2}+172,7$ & 396 \\
\cline { 2 - 4 } & 10 & $\sigma_{y}=948,7 R^{2}+177,6$ & 406 \\
\cline { 2 - 4 } & 15 & $\sigma_{y}=982,1 R^{2}+179,4$ & 416 \\
\cline { 2 - 4 } & 20 & $\sigma_{y}=1011,9 R^{2}+181,9$ & 426 \\
\cline { 2 - 4 } & 25 & $\sigma_{y}=1026,8 R^{2}+190,2$ & 438 \\
\hline \multirow{4}{*}{ Hydrodynamic } & 5 & $\sigma_{y}=677,5 R^{2}+166,5$ & 330 \\
\cline { 2 - 4 } & 10 & $\sigma_{y}=698,9 R^{2}+169,1$ & 337 \\
\cline { 2 - 4 } & 15 & $\sigma_{y}=710,6 R^{2}+172,6$ & 344 \\
\cline { 2 - 4 } & 20 & $\sigma_{y}=727,1 R^{2}+176,7$ & 352 \\
\cline { 2 - 4 } & 25 & $\sigma_{y}=763,0 R^{2}+176,7$ & 361 \\
\hline
\end{tabular}

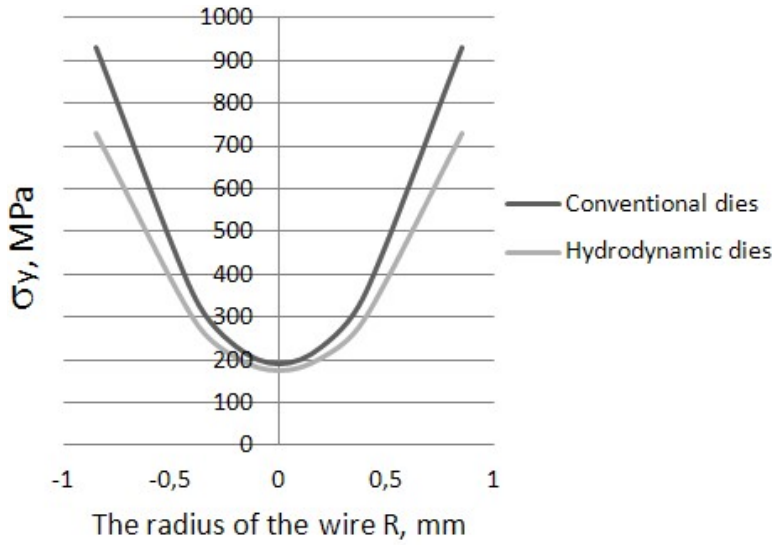

Fig. 3. The distribution of longitudinal stresses as a function of wire radius $R$ for $\phi 1.7 \mathrm{~mm}$-gauge wires drawn at speed $25 \mathrm{~m} / \mathrm{s}$ in conventional and hydrodynamic dies, respectively
Based on Table 2, a diagram has been drawn, which illustrates the effect of drawing speed on the drawing stress in $\phi 1.70 \mathrm{~mm}$-gauge wires drawn, respectively, in conventional and hydrodynamic dies (Fig. 4).

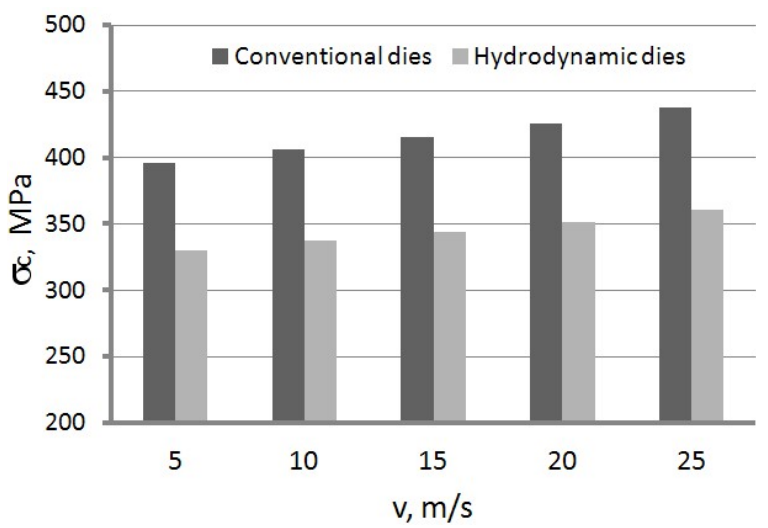

Fig. 4. The effect of drawing speed on the drawing stress in $\phi 1.70 \mathrm{~mm}-$ gauge wires drawn in conventional and hydrodynamic dies

It can be found the from the obtained numerical study results that the drawing speed significantly influences the drawing stress. It has been demonstrated that using high drawing speeds in the multi-stage drawing process contributes to an increase in drawing stress. Increasing the drawing speed from 5 to $25 \mathrm{~m} / \mathrm{s}$ resulted in an increase in drawing stress in the last draw, respectively, by about $10.5 \%$ for conventionally drawn wires and by $9.3 \%$ for hydrodynamically drawn wires. The higher drawing stress magnitudes in wires drawn at high speeds are indicative of a greater material effort, which may lead to a rupture of the wire in the drawing process.

The theoretical analysis has shown that using hydrodynamic dies in the multi-stage drawing process causes a significant reduction in drawing stress. Depending on the drawing speed, an approx. $17 \%$ drop in drawing speed was noted for wires drawn in hydrodynamic dies, compared to wires drawn in conventional dies.

The lower values of drawing stress in wires drawn in hydrodynamic dies should be associated with the better lubrication conditions at the wire-die contact, as well as lower material hardening for this drawing variant.

\section{Experimental measurement of drawing power under industrial conditions}

The experimental measurement of the drawing power in the process of multi-stage steel wire drawing in conventional and hydrodynamic dies was performed under industrial conditions on a Koch KGT 12/25 multi-stage drawing machine. This drawing machine is furnished with state-of-the-art software that is capable of directly reading out the drawing power.

Thanks to this capability, actual drawing power values, measured in individual draws, have been reported in the paper for wires drawn in conventional and hydrodynamic dies at an end speed of $v=5 \div 25 \mathrm{~m} / \mathrm{s}$. Figure 5 represents surface (after 


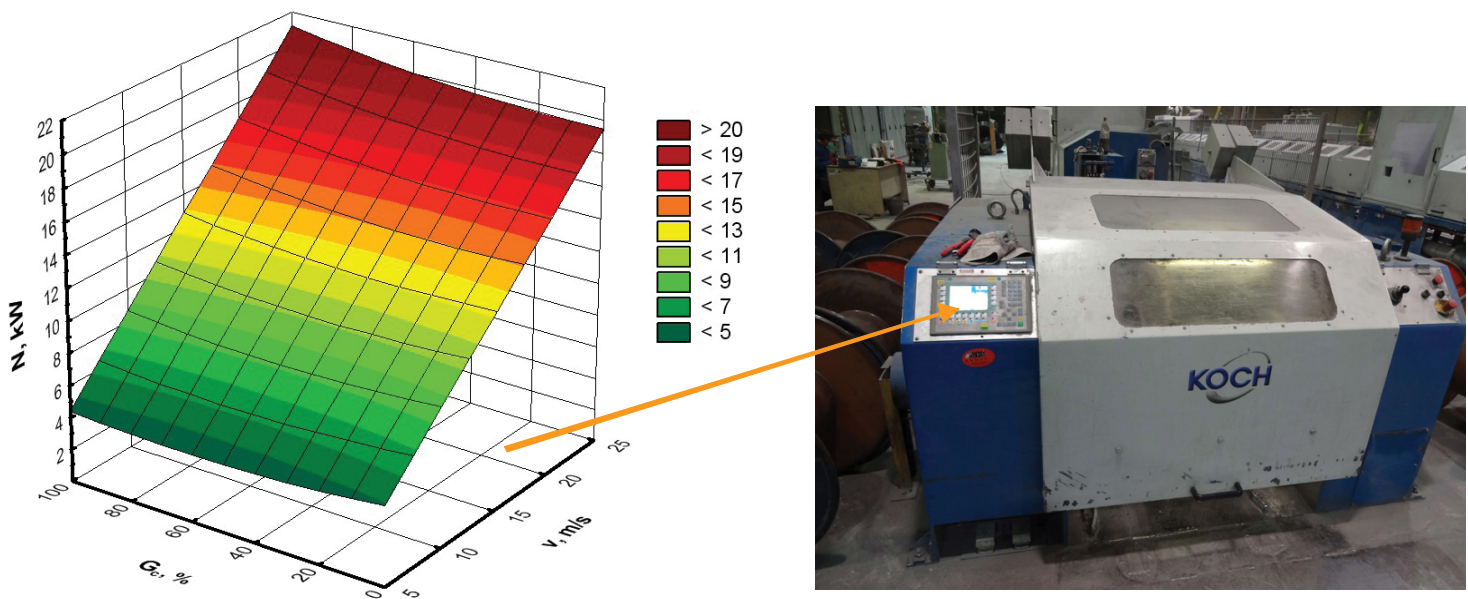

Fig. 5. A surface defining the relationship between drawing power $N$ and the total reduction $G_{c}$ and drawing speed $v$ for wires drawn in hydrodynamic dies

approximated with a function of two variables) defining the relationship between drawing power and the total reduction and drawing speed for wires drawn hydrodynamically, while Fig. 6 compares the drawing powers (reads off in the last draw) as a function of drawing speed for wires drawn in conventional and hydrodynamic dies, respectively.

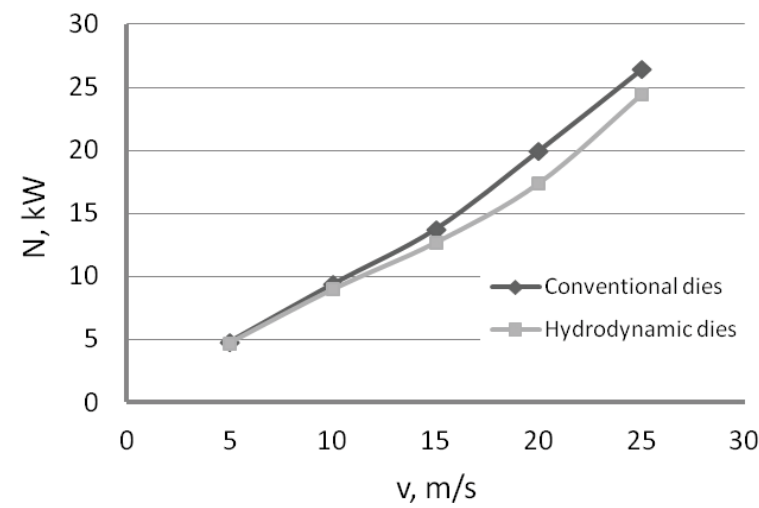

Fig. 6. Variation in drawing power (in the last draw) as a function of drawing speed for wires drawn conventionally and hydrodynamically

The test results represented in Figs. 5 and 6 show that the drawing power in the multi-stage wire drawing process is proportional to the drawing speed; specifically, the fivefold increase in drawing speed caused an approximately fivefold increase in drawing power. The performed tests have also shown that the drawing power varies only slightly in individual draws, because in the multi-stage drawing process the quantity of drawn wire on each drum is constant, and the obtained relatively small differences in power values between individual drawing stages can be linked, e.g., with the variable conditions of lubrication and friction at the wire-die contact. On the other hand, by comparing the obtained values of drawing power in the last draw for wires drawn by either of the methods, it can be found that the use of hydrodynamic dies results in a decrease in drawing power, with the differences between the analyzed variants increasing with increasing drawing speed (Fig. 6). At $v=25 \mathrm{~m} / \mathrm{s}$, an approx. 7\% drop in drawing speed was noted for wires drawn in hydrody- namic dies, compared to wires drawn in conventional dies. This is indicative of a positive influence of hydrodynamic dies on the lubrication conditions. The improvement in lubrication conditions in the drawing process contributes to a reduction of drawing force.

Literature shows a close relationship to exist between the drawing power and the drawing force. Based on formula (4) taken from study [16], the drawing force in individual draws has been calculated as follows:

$$
F=\frac{N \cdot 1000}{v}
$$

where: $F$-drawing force, $\mathrm{N} ; N$-drawing power, kW; $v$-drawing speed, $\mathrm{m} / \mathrm{s}$.

Figure 7 illustrates the effect of drawing speed and the drawing method on the drawing force in the last draw (drawing wire from $\phi 1.85 \mathrm{~mm}$ to $\phi 1.7 \mathrm{~mm}$ ), while Figure 8 represents variation in the magnitude of drawing force in individual draws for wires drawn, respectively, conventionally and hydrodynamically.

The test results illustrated in Figs. 7 and 8 show a positive effect of hydrodynamic lubrication on the drawing force. For final wires drawn in hydrodynamic dies, depending on the drawing speed, drawing force magnitudes smaller from 2 to $7 \%$ compared to wires drawn in conventional dies have been noted, whereas,

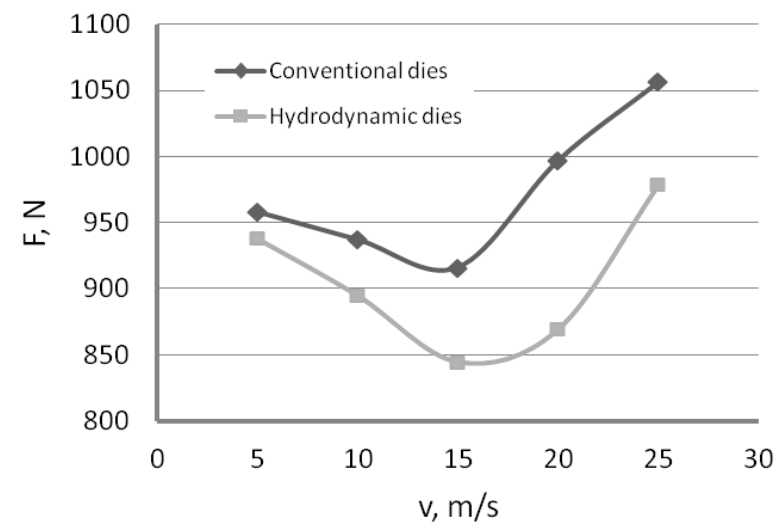

Fig. 7. The effect of drawing speed on the drawing force magnitude for wires drawn in conventional and hydrodynamic dies (the last draw) 


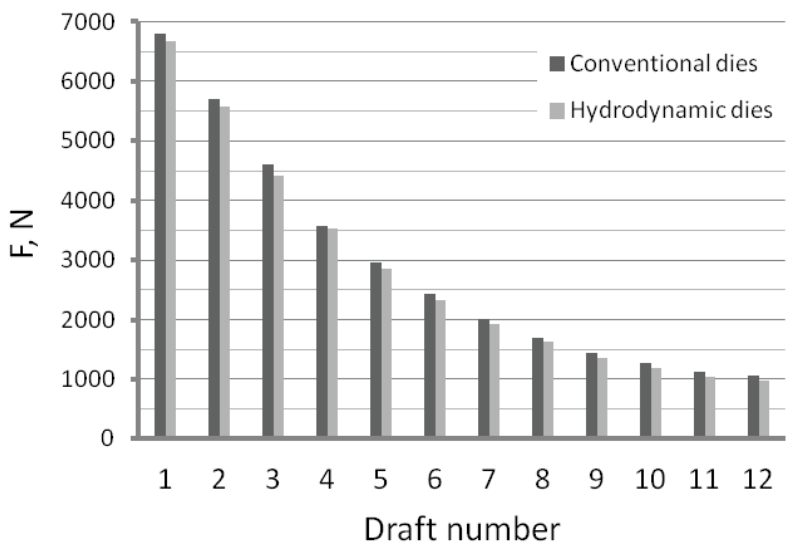

Fig. 8. Variation in the magnitude of drawing force in individual dies for wires drawn in conventional and hydrodynamic dies (at $v=25 \mathrm{~m} / \mathrm{s}$ )

the higher the drawing force, the larger the differences between the variants under analysis. It has also been found that, within the specified range, the increase in drawing speed $(v=5 \div 15 \mathrm{~m} / \mathrm{s})$ results in a decrease of drawing force, which can be explained, inter alia, by the improvement in lubrication conditions (Fig. 7). Further increasing the drawing speed up to $v=25 \mathrm{~m} / \mathrm{s}$ resulted in a marked increase in drawing force. For wires drawn in conventional dies, the increase in drawing force should be associated with the considerable impairment in lubrication conditions, caused by intensive heating of the wire. On the other hand, in the case of wires drawn in hydrodynamic dies at $v=25 \mathrm{~m} / \mathrm{s}$, the drawing force increase should be linked with the hydrodynamic effect, which caused an additional deformation of the wire. The actual diameter of wire drawn hydrodynamically at a velocity of $25 \mathrm{~m} / \mathrm{s}$ was $1.63 \mathrm{~mm}$, while for the remaining drawing variants, $1.7 \mathrm{~mm}$.

Based on the obtained drawing force values, drawing stresses in individual draws were calculated for wires drawn in conventional dies and hydrodynamic dies. The results are presented in Figs. 9-10. To verify the correctness of the assumed boundary conditions in numerical modelling, the drawing stress values obtained from simulation were compared with the experimental results (Fig. 11).

From the obtained results it can be found that, at a given total reduction, depending on adopted drawing parameters, such as lubricants or drawing methods, increasing the drawing speed may result either in an increase or a decrease of drawing stress

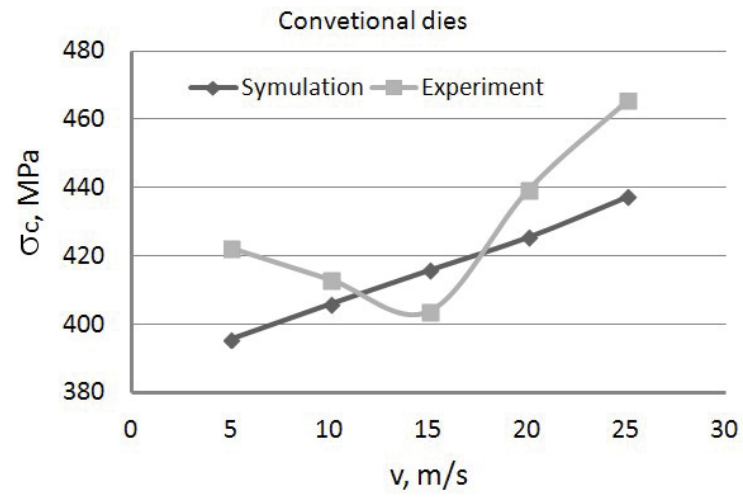

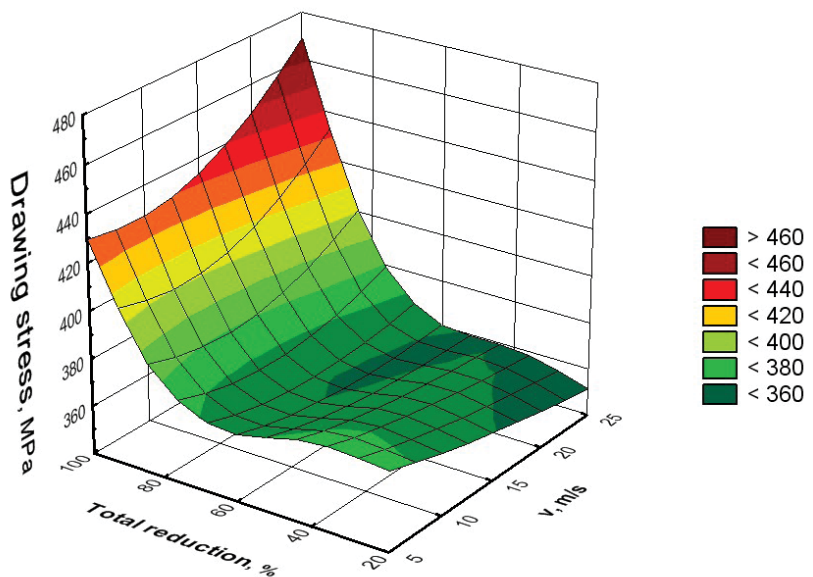

Fig. 9. A surface defining the relationship between drawing stress $\sigma_{c}$ and the total reduction $G_{c}$ and drawing speed $v$ for wires drawn in conventional dies

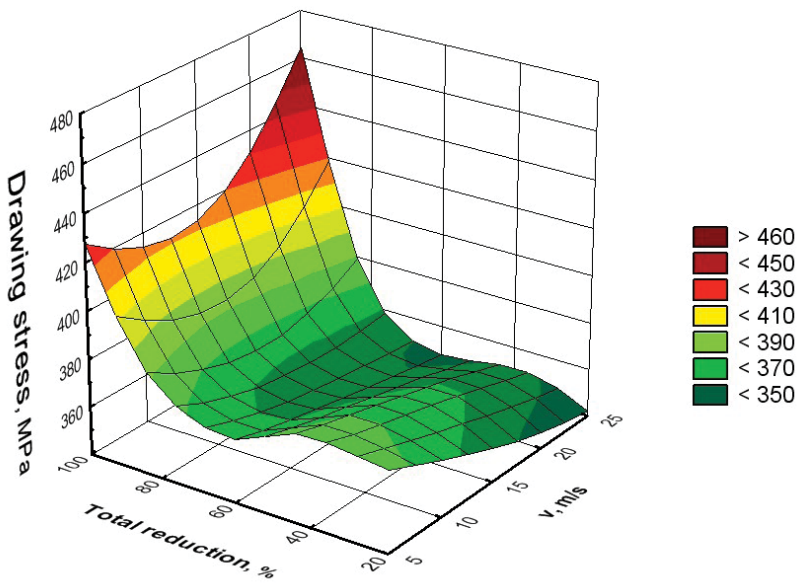

Fig. 10. A surface defining the relationship between drawing stress $\sigma_{c}$ and the total reduction $G_{c}$ and drawing speed $v$ for wires drawn in hydrodynamic dies

(Figs. 9 and 10). A negative effect of high drawing velocities becomes only visible at drawing speeds exceeding $15 \mathrm{~m} / \mathrm{s}$, and it may be reduced by using hydrodynamic dies in the drawing process, whereas, the decrease in drawing stress in wires drawn in those dies do not exceed $15 \%$. The data represented in Figure 11 shows that the mathematical models adopted in the program adequately simulate the distribution of longitudinal stress

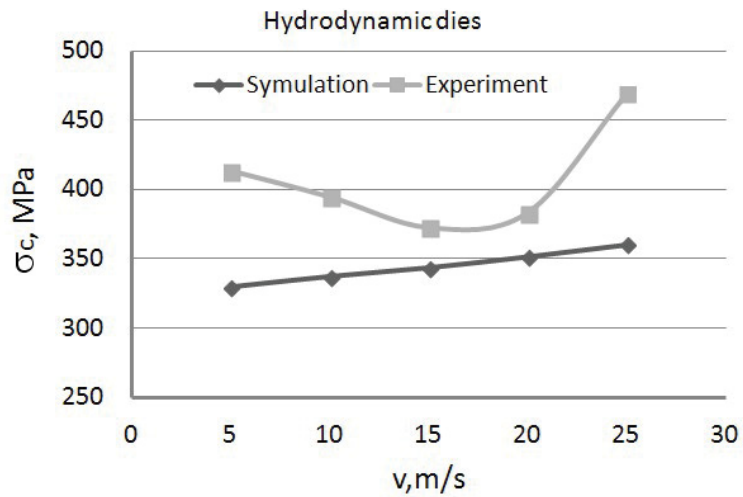

Fig. 11. Variation in drawing stress in the last draw as a function of drawing speed for wires drawn in conventional and hydrodynamic dies 
and drawing stress, since at the assumed friction coefficients of $\mu=0.08$ and $\mu=0.03$, the maximum difference between the stresses determined from simulation and calculated based on the measured drawing powers does not exceed $25 \%$. In modelling, a constant value of friction coefficient was assumed, whereas in the actual drawing process, the friction coefficient value depends on the lubricant rheology and drawing technology, and especially on the drawing speed. Preliminary tests carried out by the author of [11] have shown that, in the process of multi-stage drawing in the drawing speed range of $v=2.5 \div 20 \mathrm{~m} / \mathrm{s}$, the value of the friction coefficient for conventional drawing ranges from 0.065 to 0.09 . Hence, for the sake of simplification, the average friction coefficient identical in all draws was assumed in the modelling. For hydrodynamic drawing, the value of the friction coefficient was assumed based on literature data which shows that, in the hydrodynamic drawing process, the friction coefficient value is contained in the range from 0.005 to 0.03 . In the author's view, the higher drawing stress values obtained experimentally may indicate that in the real process of drawing in hydrodynamic dies the friction coefficient value is higher that that suggested by the literature. The theoretical analysis of hydrodynamic drawing did not consider the effect of back-tension on the drawing stress, which causes an increase in drawing stress. Moreover, as has been shown by the experimental tests, wires drawn in hydrodynamic dies may show dimensional deviations, which are not allowed for by numerical analysis.

\section{Conclusions}

1. The investigation carried out has confirmed the significant effect of drawing technology on the force parameters of the steel wire drawing process.

2. The use of hydrodynamic drawing dies enables a reduction in drawing stress to be achieved, which ranges from 2 to $7 \%$, depending on the total reduction. At high drawing speeds of around $25 \mathrm{~m} / \mathrm{s}$, under hydrodynamic lubrication conditions, an increase in drawing stress is likely due to an additional wire deformation caused by the lubricant.

3. A significant effect of drawing speed on the force parameters has been shown to exist in the process of drawing wire in both conventional and hydrodynamic dies. Depending on the actual drawing conditions, increasing the drawing velocity may result in either an increase or a decrease in drawing stress.

4. The appropriate selection of the friction coefficient in computer simulations enables the estimation of the force parameters of the drawing process. The maximal difference between the stresses determined from simulations and calculated based on measured drawing powers did not exceed $25 \%$. In modelling, a constant friction coefficient value was assumed, whereas in the actual drawing process, the friction coefficient value depends on the lubricant rheology and drawing technology, and especially on the drawing speed.

\section{REFERENCES}

[1] M. Suliga, Analysis of the multipass steel wire drawing with high speed in conventional and hydrodynamic dies (Analiza wielostopniowego ciągnienia drutów stalowych z dużymi prędkościami w ciaggadłach konwencjonalnych i hydrodynamicznych - in Polish), monograph No. 32. Czestochowa University of Technology, Publishing House of the Faculty of Process and Materials Engineering and Applied Physics: Czestochowa (2013).

[2] M. Suliga, Analysis of the heating of steel wires during high speed multipass drawing process. Archives of Metallurgy and Materials 59, 4, 1475-1480 (2014).

[3] S. Mroz, Influence of Non-Uniform Temperature Distribution on Metallic Charge Length on Energy and Force Parameters During Groove-Rolling, Journal of Iron and Steel Research International 8, 19, 17-24 (2012).

[4] A. Stefanik, S. Mroz, P. Szota, H. Dyja, Determination of slitting criterion parameter during the multi slit rolling process, Conference: 9th International Conference on Numerical Methods in Industrial Forming Processes NUMIFORM '07: Materials Processing and Design: modeling, simulation and applications, PTS I AND II Book Series: AIP Conference Proceedings 908, Part 1-2, 1231-1236 (2007).

[5] S.M. Byon, S.J. Lee, D.W. Lee, Y.H. Lee, Y. Lee, Effect of coating material and lubricant on forming force and surface defects in wire drawing process, Transactions of Nonferrous Metals Society of China, 104-110 (2011).

[6] P. Enghag, R. Larsson, K. Pettersson, Investigation of force and friction in wire drawing, Wire Industry May, 272-277 (2001).

[7] I.Ł. Pierlin, M.Z. Jermanok, Teoria volochenia, Moskva, Izd. Metallurgija 1971.

[8] M. Schneider, Ciagarstwo, WGH, Katowice 1961.

[9] J. Łuksza, Elementy ciagarstwa, AGH, Kraków 2001.

[10] F.Schwier, Beitrag zur Frage der mechanischen Alteryng bei hartgezogenen patentierten Stahldrähten, Stahl und Essen 2, 59-66 (1952).

[11] M. Suliga, The influence of high drawing speed on the process parameters in manufacture of high carbon steel wires, Steel Research International, Special Edition, Proceedings of the 14th International Conference on Metal Forming, METAL FORMING 2012, Akademia Górniczo-Hutnicza, Kraków, Poland, 16-19 September 2012, 491-494 (2012).

[12] B. Avitzur, Handbook of Metal-Forming Processes, A Wiley Interscience publication, John Wiley \& Sons, New York, 1983.

[13] B. Golis, H. Dyja, Niektóre zagadnienia procesu ciagnienia drutu przez ciagadła ciśnieniowe, Hutnik 12, 399-404. (1991).

[14] A. Milenin, P. Kustra, Mathematical model of warm drawing process of magnesium alloys in heated dies, Steel Research International 81, 9, 1251-1254 (2010).

[15] Z. Muskalski, Analiza wpływu kierunku ciągnienia drutów na ich wytrzymałość zmęczeniową i trwałość zmęczeniową lin stalowych, Seria Metalurgia nr 43, Politechnika Częstochowska, Częstochowa 2004.

[16] P. Enghag, Steel Wire Technology, Repro Örebro Universilty, Örebro 2010. 